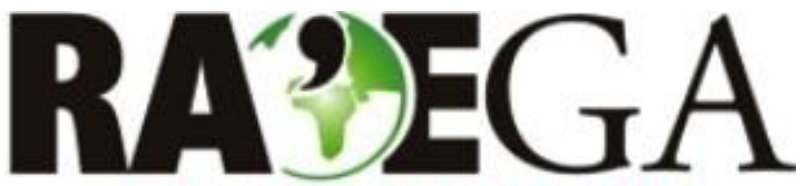

O ESPACYO GEOGRÁFICO EM ANÁLISE

\title{
JOGOS PAISAGÍSTICOS: MAPAS E ATLAS COMO CONCEITOS OPERATIVOS
}

\section{LANDSCAPE GAMES: MAPS AND ATLAS AS OPERATIVE CONCEPTS}

\author{
Frederico Canuto \\ Departamento de Urbanismo \\ Universidade Federal de Minas Gerais \\ Belo Horizonte, MG \\ E-mail: fredcanuto@gmail.com
}

Recebido em: 03.06.2013

Aceito em: 03.12.2013

\section{Resumo}

O presente artigo coloca em discussão a produção de paisagens como prática que pode envolver diferentes agentes e percepções, não sendo estreitamente vinculado a um único olhar dito objetivo. A partir de tal discussão, mapas e atlas, instrumentos cartográficos por demais usuais, são aqui transformados em conceitos para se pensar a paisagem e sua produção na contemporaneidade levando em conta diferentes recortes epistemológicos, pontos de vista, agentes e sujeitos. Usando o conceito de espasmos advindo da critica do filósofo francês Gilles Deleuze a respeito das pinturas Francis Bacon, tais operadores serão discutidos como espaços autônomos de produção de paisagens a despeito de qualquer imagem exterior existente a priori. Serão usadas duas obras que, por sua vez, apontarão para a definição destes mesmos operadores: o trabalho artístico participativo Alter Bahnhof Vídeo Walk dos artistas Janet Cardiff e George Miller apresentado na DOCUMENTA XIII de Kassel em 2012 e o site interativo We feel Fine. An Exploration of Human Emotion, in Six Movements feito pelos designers Jonathan Harris e Sep Kamvar. E na conclusão, pretende-se discutir o mapa e atlas não como instrumentos de leitura de um real, mas eles mesmos como um real narrativo.

Palavras-chave: Paisagem; espasmos; cartografia; narrativas. 


\begin{abstract}
This article discusses the production of landscapes as a practice that could involve different actors and perceptions that are not necessarily linked to an exclusive and objectified view. For this discussion, maps and atlases, the most common cartographies, are transformed in concepts to discuss landscape and its construction in contemporary times, linked with different epistemologies, points of view and subjects. Using the concept of Spasm created by French philosopher Gilles Deleuze on his writings about Francis Bacon's paintings, such operators are going to be discussed as autonomous definitions regarding the production of landscapes. Two works are going to be used in order to define theses map and atlas concepts: the artistic-collaborative work of Janet Cardiff and George Miller Alter Bahnhof Video Walk presented in DOCUMENTA XIII in 2012 and the interactive site We feel Fine. An Exploration of Human Emotion, in Six Movements made by the designers Jonathan Harris and Sep Kamvar. And finishing the essay, map and atlas are discussed not as reading instruments of the reality, but as a reality field, a narrative.
\end{abstract}

Keywords: Landscape; spasm; cartography; narrativas.

\title{
INTRODUÇÃO
}

Desde os anos 1960, a questão da paisagem tem se tornado central quando pensada numa esfera ambiental. Não somente porque o meio ambiente tornou-se preocupação mundial com movimentos sociais reivindicando desde então uma relação menos danosa entre este e o homem, mas também porque a partir deste momento, os modos de construir olhares sobre a realidade passam por uma construção representativa que coloca em consideração sua própria artificialidade a partir do olhar lançado. A paisagem é sempre uma construção artificial por ser humana. Desde então, as artes plásticas e os campos disciplinares interessados nas categorias ambientais e suas epistemologias, como a antropologia, geografia e urbanismo, focam nesse modo de olhar. A principal questão para estes é dimensionar a representação do mundo como construção do mesmo dado na relação artista/antropólogo - espaço/paisagem, usando aqui a aproximação arteantropologia a partir do texto preciso de Freire (2006) no qual afirma sobre a arte: "A obra como documento incorpora o transitório do tempo e ensina sobre a fugacidade da vida. (...) Na relação entre o objeto e o registro, a obra se torna índice de algo ausente" (FREIRE, 2006, p.113). 
Num breve histórico, a paisagem na arte do século XVIII é problematizada e, logo, representada primeiramente, como uma natureza desmesuradamente desconhecida e até mesmo assustadora, reflexo de um estado de espírito delineado nas telas dos pintores românticos, dos quais Caspar David Friederich é um dos maiores. Paisagem como imagem a ser esquadrinhada e geometrizada da natureza a fim de ser incorporada dentro da cidade como jardim ou parque pelos paisagistas no século XIX é o próximo passo dado na Modernidade via urbanismo. Paisagem como o que está lá fora, à vista, distante do toque, mas ao alcance do olhar que enquadra o é para os modernos durante meados do século $\mathrm{XX}$, como nos famosos croquis do arquiteto Le Corbusier em que o esse está de frente a uma janela observando o mundo do outro lado do vidro, como bem observado no ensaio crítico de Iñaki Abalos (2013) denominado "O que é a paisagem". E assim, finalmente, a paisagem como produto de uma narrativa que a problematiza como fabulação mais do que descrição é, conceitualmente, o lugar em que o campo se encontra hoje dentro dos estudos envolvendo-a, principalmente devido a esforços de diversas linhas de pensamento da arquitetura e das artes plásticas como a Land Art, assim como da própria antropologia e outras ciências sociais, em torná-la espaço de exercício de Poder.

Desta forma, o objetivo aqui deste trabalho é discutir as imagens da paisagem, usando de seus mais usuais instrumentos de medição e cartografia mapa e atlas -, como espaços narrativos próprios e autônomos, transformados em conceitos operativos a partir do conceito espasmo.

\section{MÉTODOS}

De objeto, a paisagem como colocado anteriormente torna-se hoje conceito operativo para pensar a esquizofrenia em que nossos aparelhos perceptivos encontram-se: as múltiplas escalas e variadas informações de diferentes fontes associadas à diversidade de suas formas de representação e, até mesmo, apresentação, produzem algo como um espasmo em nossa sensibilidade, se a associarmos as considerações de Deleuze sobre as pinturas de Francis Bacon em "Lógica das Sensações" (DELEUZE, 2007).

Segundo o filosofo francês Deleuze (2007), ao comparar o método de pintura 
de Bacon com o do pintor americano Jackson Pollock e o pintor russo Wassily Kandinsky, percebe que ele pinta diferentemente: "Bacon segue uma terceira via, nem ótica, com a pintura abstrata, nem manual, como a Action Painting" (DELLEUZA, 2007, 102-112). Como coloca o crítico Roberto Machado (2009), espasmo é termo usado para descrever a pintura de Bacon e sua forma diagramática - "Deleuze chama de diagrama o conjunto operatório de manchas e traços irracionais, involuntários, acidentais, automáticos, livres, ao acaso, que são não representativos, não ilustrativos, não narrativos" (MACHADO, 2009, p.241). Nas pinturas do artista, subtraindo as formas mais convencionais que geralmente ocupam a periferia da pintura (Figura 1) ou mesmo que dão suporte a forma diagramática em outros casos, o que é percebido são linhas de força, sensações: não um momento congelado como a fotografia faz, nem múltiplas imagens do tempo decompostas e retratadas todas num mesmo espaço pictórico como as pinturas cubistas de Pablo Picasso ou Marcel Duchamp, mas momento de formação como um ponto de transição permanente. A transição é a figura/forma final. E este estado permanente transicional é o espasmo, um movimento de contorção ou retração na qual o corpo tenta escapar de sua própria forma. Um movimento de permanente devir. E é neste ponto, a não a partir dele, que nossos aparelhos perceptivos se encontram e produzem sensações. Nesse ínterim transformado em agora, corpos perdem identidades genéricas e podem tudo, sendo transformado em imagens em constante mutação.

A paisagem é o se vê e não se vê, mais além, como se percebe. As pessoas estão em diversos lugares num mesmo tempo: como informação geográfica via satélite até unidades de uma massa de indivíduos que habita as cidades. Não se pensam a paisagem ou a natureza, mas na natureza, como parte integrante, porque construtora da mesma. Tanto o conteúdo como a própria forma de construção de uma paisagem, assim como seu recorte epistemológico, são abordagens interrelacionadas que aprofundam uma artificialidade que está intrínseca à própria noção de paisagem, visto que é produto interessado e não reflexo-cópia tal qual um real. Para tanto, não gratuitamente, a filósofa Anne Cauquelin (2008) afirma que a categoria se acha construída desde sempre a partir da noção de jogos paisagísticos - jogos entre quem olha e o que se olha. 


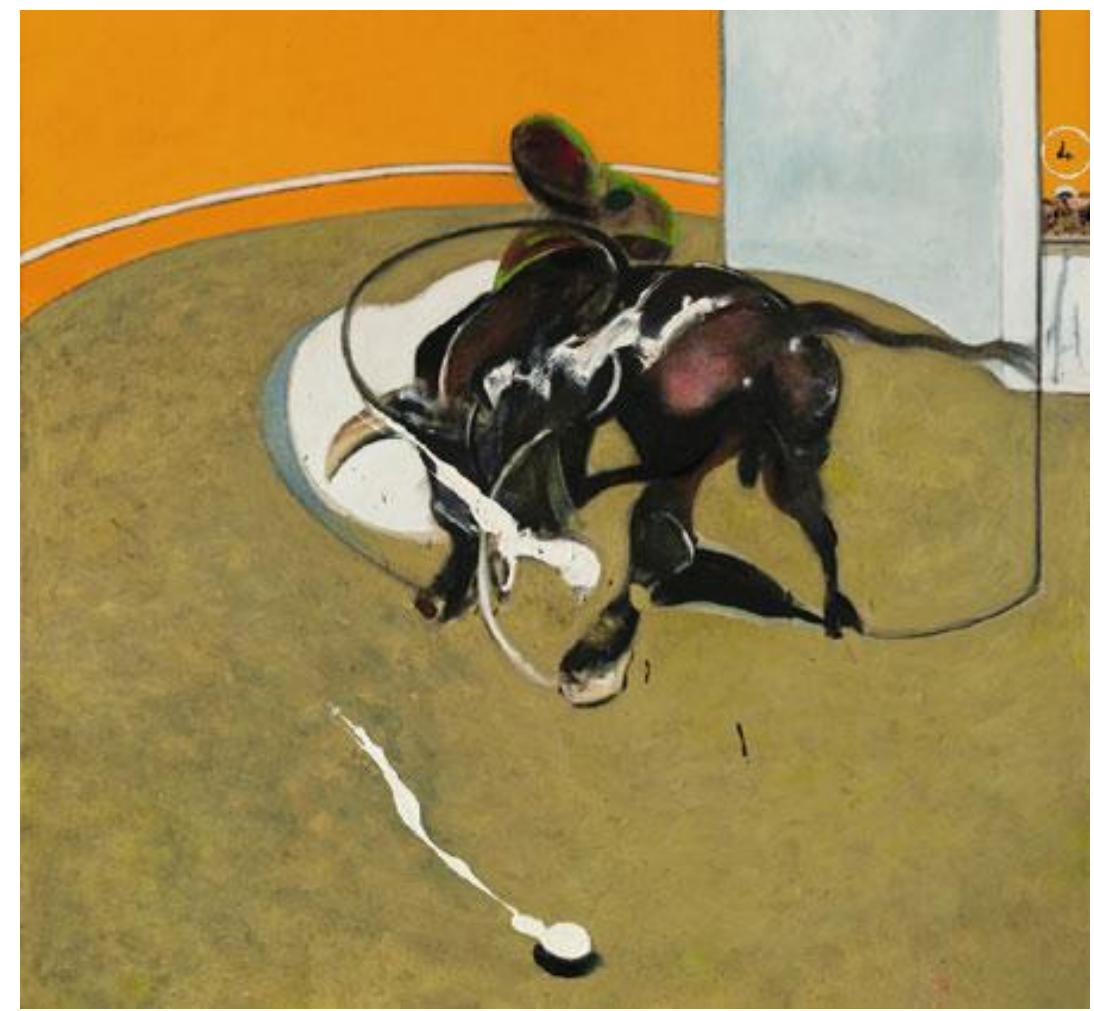

Figura 01: Francis Bacon. Study Bullfight No1 $2^{\text {nd }}$ version.

Fonte: http://www.bornrich.com/entry/francis-bacons-bullfight-valued-at-more-than-35-million/, acessado em 11/10/2012.

Estes jogos paisagísticos são definidos por esta ambivalência ou espasmo enquanto "compossibilidade" perceptiva porque agrega diversas percepções possíveis criando imagem múltipla e em constante mudança, convergente por princípio. São jogados/experimentados de modo radical e cotidianamente ao se caminhar na cidade com duas imagens de mapa à mente: um desenhado pela experiência no local e outro, Google Earth, esquadrinhado pelos smartphones à mão. Ou o contrário: no dia-a-dia, as pessoas se conectam à internet, deambulam pelo Google Earth para encontrar aquele lugar que já conhecem. Tal espasmo dado pela problematização da paisagem, em que estão como parte da construção da mesma, é território onde os trabalhos de arte mais frutíferos estão sendo produzidos numa estreita relação a partir do conhecimento espacial em suas mais variadas formas. Propostas que tentam fazer deste uma zona de discussão dos modos como se vê e são construídas imagens vis-à-vis suas dimensões espaço-temporais, e para 
a presente discussão, de forma potente, que ao mesmo tempo tentam nos ressensibilizar a partir do que se vê, mas que não está ali à frente.

\section{MATERIAIS}

A partir de uma interpretação crítica do trabalho artístico participativo Alter Bahnhof Vídeo Walk dos artistas Janet Cardiff e George Miller apresentado na DOCUMENTA XIII de Kassel em 2012 (CHRISTOV-BAKARGIEV, 2012), serão discutidos os modos como tal sobreposição representativa pode produzir diferentes leituras no local por parte dos que ali experimentam a obra, construindo novas paisagens onde parecia não haver nada de novo e novos modos de apreender contextos. Assim, estará em discussão como uma cartografia desse tipo é capaz de produzir um mapa espaço-temporal aberto à interferência dos múltiplos agentes que ali produzem seu próprio espaço e leitura. Desta forma, pensar esta obra como um mapa onde possíveis e múltiplas paisagens são produzidas por um recorte epistemológico fundado no comum como categoria que agrega o que é diverso.

E por meio do trabalho da dupla de designers Sep Kamvar e Jonathan Harris, autores do site interativo We Feel Fine, serão destacadas as possibilidades de leitura e visualização - portanto representação - que tais mapas quando em conjunto são capazes de gerar. Ou seja, pretende-se discutir a dimensão atlas da obra, não apenas por se tratar de um conjunto de mapas, mas porque também afirma uma unidade que irradia uma possibilidade infinita de leituras e interpretações quando do cruzamento de informações construídas pelos mais diferentes agentes.

\section{DISCUSSÃO}

\section{Mapa}

Ao percorrer as ruas de Kassel à procura das obras da DOCUMENTA XIII, na Alemanha, surge o Terminal Ferroviário da cidade. Adentrando, vê-se várias pessoas munidas de ipods caminhando e olhando para o espaço, rindo e olhando tanto para a tela do celular/tocador como para o espaço vazio. Essa é a cena vista ao chegar à obra dos artistas Janet Cardiff e George Miller (Figura 02). Essa é a cena de hipnose coletiva, onde apreciadores de arte se confundem com transeuntes 
usando seus celulares sem qualquer relação com a obra de arte em si (Figura 03), aparentemente.

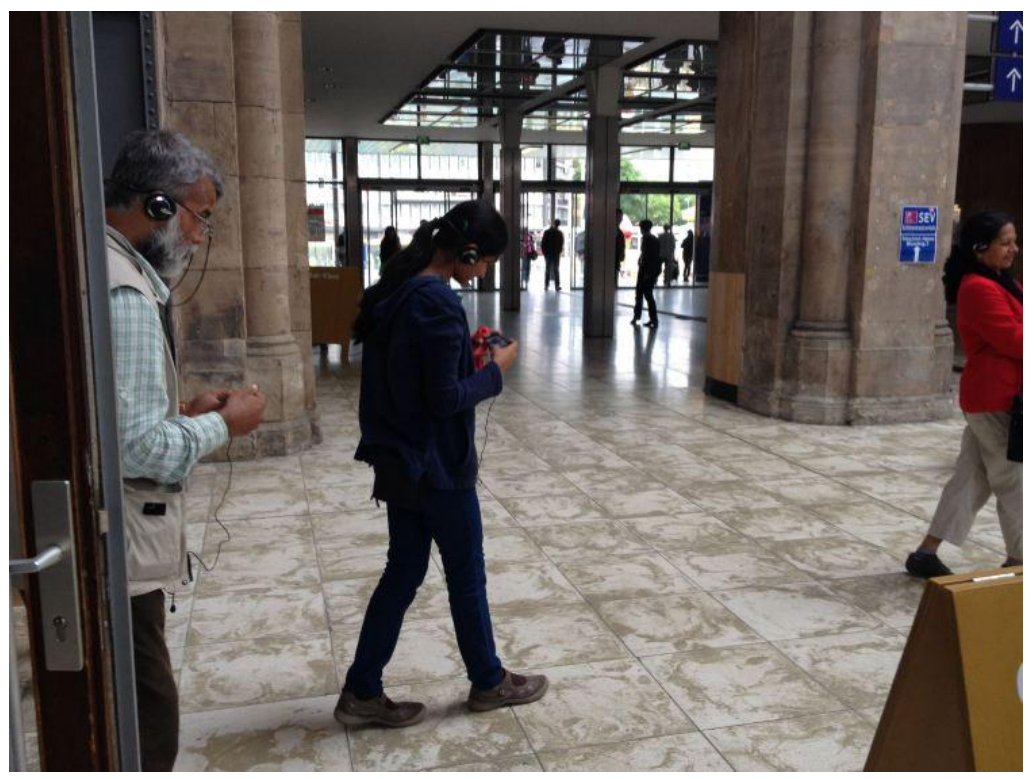

Figura 02: Alter Bahnhof walkers

Fonte: http://accaartblog.com/, acessado em 10/11/2012.

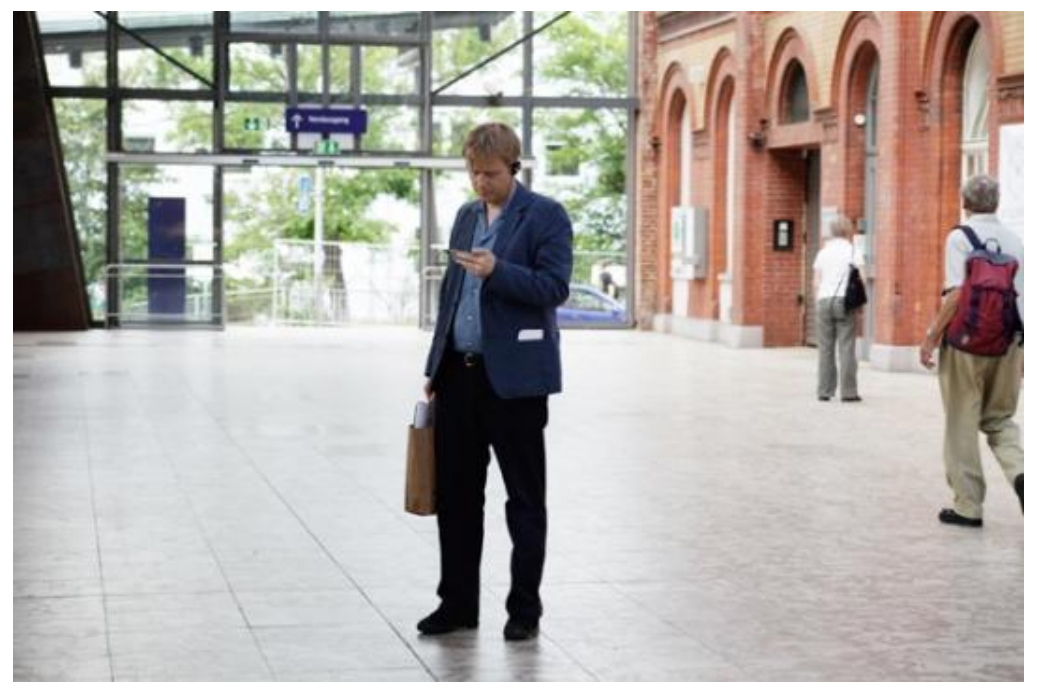

Figura 03: Alter Bahnhof walkers

Fonte: http://d13.documenta.de/\#/panorama/, acessado em 10/11/2012.

Assistir a um dos vídeos feitos em primeira pessoa postado no youtube por uma das pessoas que participaram dessa experiência estética ${ }^{1}$, é possível perceber como o construto artístico feito pela dupla se dá de maneira simples e potente. A

\footnotetext{
${ }^{1} \mathrm{http}: / /$ www.youtube.com/watch?v=sOkQE7m31Pw
} 
pessoa entra no Terminal, adentra uma loja indicada, vai até um balcão e recebe, para ver a obra, um ipod com um fone de ouvido. Neste momento, a ajudante lhe dá as instruções: ir à frente da loja onde o ipod foi pego, sentar-se num banco específico em frente da vitrine e ligar o vídeo. E durante todo o processo que se dará daí por diante, ao ver as imagens e ouvir o áudio, obedecer às instruções dadas pela voz gravada de Cardiff. Assim é iniciada uma experiência sinestésica por meio da qual passado e presente, real e virtual, visão e prospecção, audição e fabulação se fundem, construindo uma paisagem onde sua unicidade é dada porque a obra é exe in situ.

Ex Situ. Ao caminhar pela estação a partir das instruções de Cardiff, vê-se no espaço do terminal pela tela HD do ipod - dado este importante, pois High Definition traduz-se publicitariamente como "mais que o real", ironia para um vídeo que é reflexo/transformação do que é real - o passeio da artista já feito e entremeado de imagens de sonho, de sons outros que são tanto parte do ambiente existente no dia que ela ali gravou, como de intervenções por ela produzidas para o lugar. É possível ver na tela, tornada automaticamente prótese porque os olhos estão voltadas o tempo inteiro para ela, as imagens da artista, a ponto dos olhos ou visão dela se tornar a de quem participa da obra, carregando o portátil. $\mathrm{Na}$ tela bailarinas dançando ao som de uma banda pela entrada do Terminal, performances colocadas ali por Cardiff e Miller.

In Situ. O que dá complexidade a obra é o fato de que, ao mesmo tempo em que olhos e ouvidos estão focados nas informações vindas do ipod, o espaço do Terminal à volta naquele momento é presente, porque ao obedecer caminhando o roteiro da artista, esbarra-se na materialidade do espaço arquitetônico existente.

Ex-In Situ ou sobre uma compossibilidade (Figura 06). Ao caminhar e ver/observar o terminal ao mesmo tempo que vendo/ouvindo-o pela tela, um ambiente imersivo se desenha e nele se submerge. As fronteiras entre o que é real e o que é virtual, entre o que acontece e não acontece lá, são fundidas. É como estar afogando quando uma onda empurra no mar: nunca se sabe se está fora ou dentro d'água porque as imagens e os sentidos do próprio corpo se confundem. Uma pessoa ao passar na frente do vídeo feito por Cardiff ex situ faz desviar do corpo da mesma no espaço in situ. É tornado possível uma virtualidade dentro do real, sem 
que isso seja menos real. Há uma possibilidade dupla de que ambas as caminhadas ou passeios sejam reais porque interferem no modo como o corpo se porta no terminal. O caminhar com o corpo modificado pelo aparelho portátil produz uma ambigüidade pactual entre o olhar do portador do aparelho e o olhar dos autores do vídeo, esmaecendo limites.

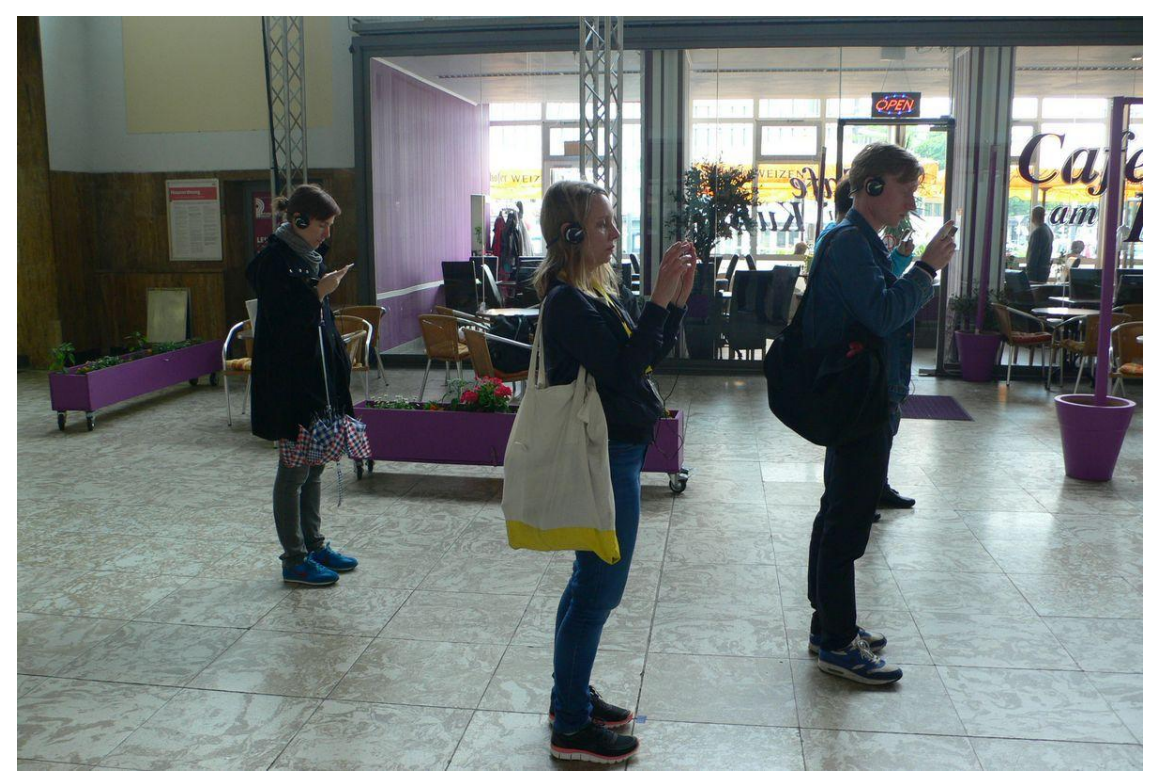

Figura 04: Alter Bahnhof vídeo walk.

Fonte: http://www.revistabrasileiros.com.br/2012/06/12/artebrasileiros-na-documenta-13-3/, acessado em 10/11/2012.

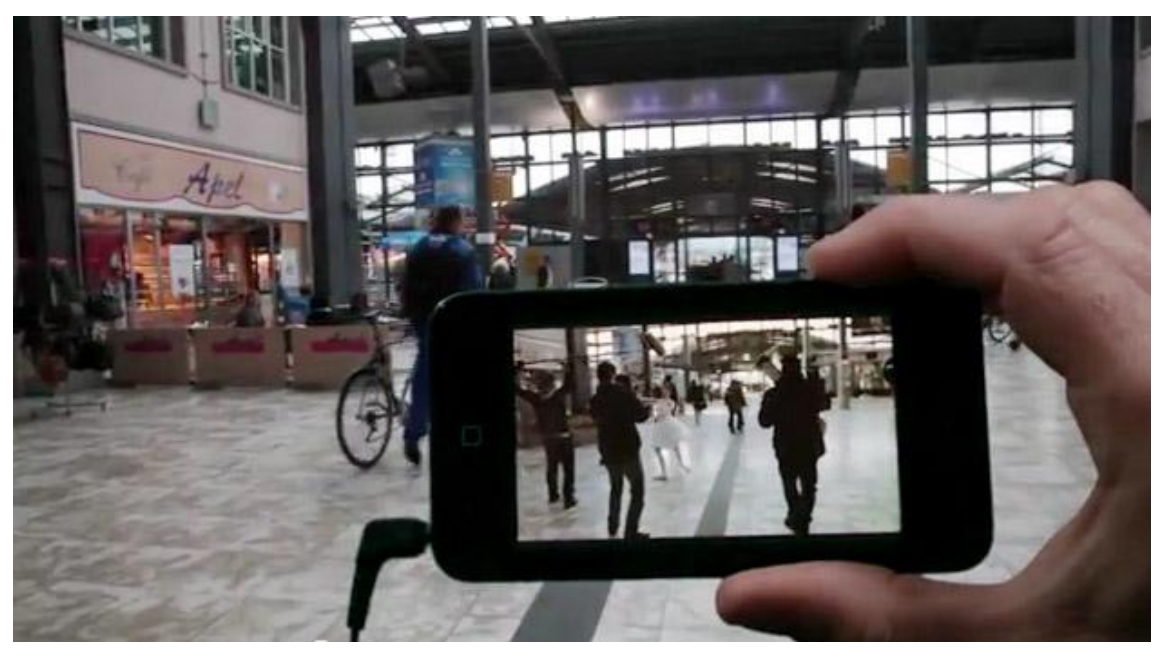

Figura 05: Alter Bahnhof vídeo walk.

Fonte: http://accaartblog.com//, acessado em 10/11/2012. 


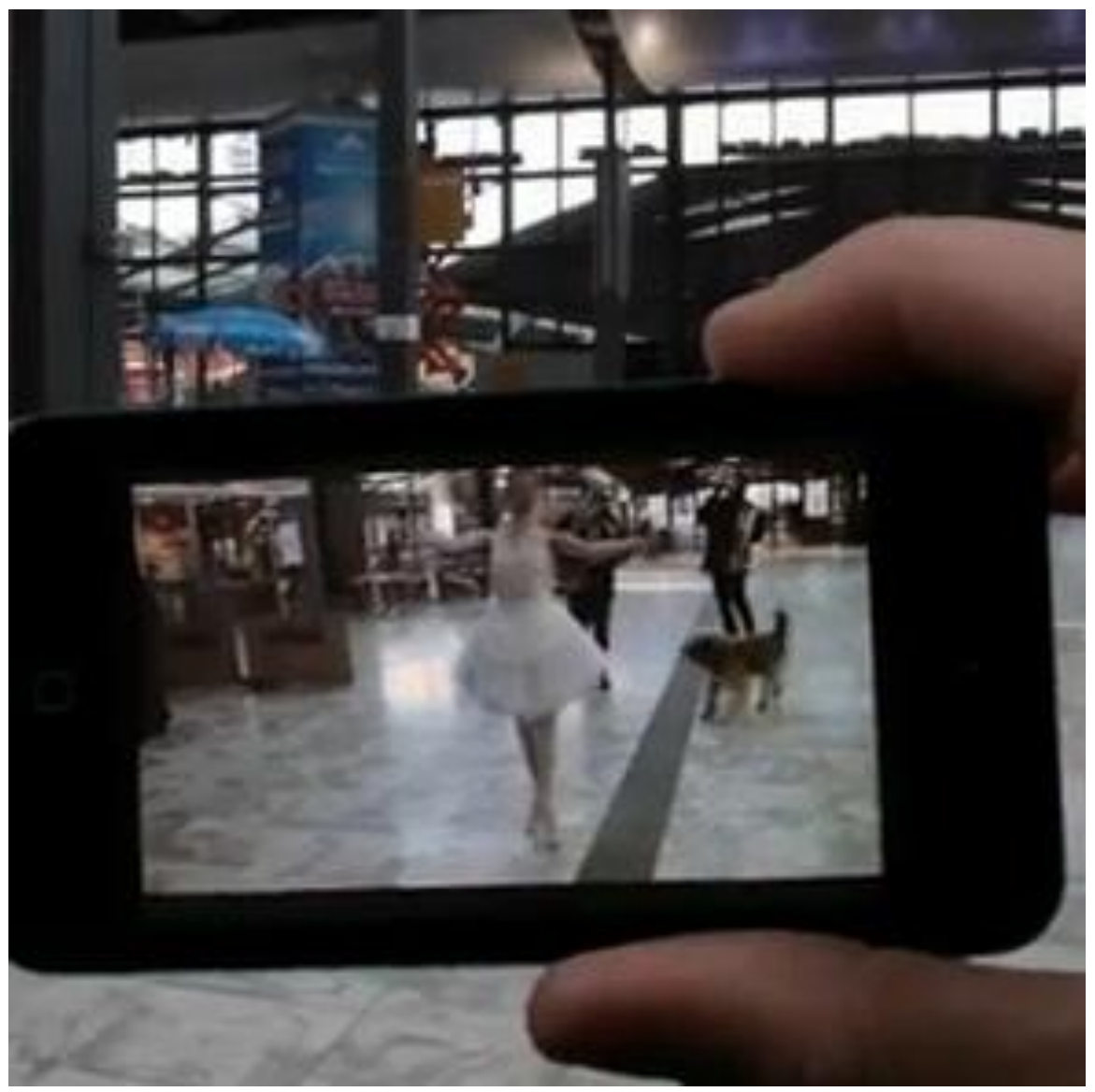

Figura 06: Alter Bahnhof vídeo walk.

Fonte: http://manpodcast.com/post/28268352547/this-weeks-modern-art-notes-podcast-features, acessado em 10/11/2012.

Esse passeio sobre lugares da Modernidade como este Terminal Ferroviário, definido por Marc Augé (2007) como não-lugar porque espaço de relacionamentos fracos e destendidos, só vem a mostrar esta dupla possibilidade que é vislumbrada por este mesmo antropólogo em sua definição do termo. Não-lugar para Augé ambivalentemente se define como espaço do consumo, do não permanente, do transitório, ao mesmo tempo em que é lugar que aponta para um lugar outro, que não os lugares genéricos produzidos na Modernidade. Aqui, o terminal, lugar de passagem, é negativo pois abre para outros reais, outros possíveis em tempos outros.

Ainda mais interessante é como tal experiência coloca a paisagem como construto que é dado num espaço e tempo bem definidos em questão. Normalmente ao se produzir cientificamente um mapa, este pertence a um contexto bem definido. O autor como sujeito é indiferente porque este obedece a uma série de normas 
cartográficas que tendem a uma suposta objetividade e imparcialidade. Mas neste experimento da dupla de artistas, há uma inversão de valores ou o caráter científico como verdade é substituído pelo que ele carrega de hipotético.

O mapa produzido pela dupla e que é continuado pelo sujeito que coloca os fones de ouvido, a cada leitura, a cada passeio, transforma-se ao solicitar não uma posição de espectador, mas de engajados e participantes na produção de um sentido. Pede leituras prazerosas. É um contexto bem definido, mas elástico e múltiplo porque o tempo pode ser qualquer indefinido desde que considerado sobreposto a outro tempo, o dos artistas. Não há imparcialidade, mas subjetividade na construção de uma narrativa que pensa a memória, em termos benjaminianos, não como reprodução do passado, mas fabulação incessante porque é situacional e contingente, dada nos rastros do que ficou pra trás (BENJAMIN, 2006). A referência não é verdade, mas direção aberta.

\section{Atlas}

O atlas normalmente é pensado como conjunto de mapas. Potencialmente, então, se o mapa é cartografia e imagem de um lugar, o atlas é construto onde todas as imagens de lugares coexistem. Nessa abordagem totalitarista, o atlas é um todo. Entretanto, ele é por si mesmo mapa da mesma maneira, pois é um mundo dentro de mundos possíveis variados visto que mapas podem ser muitos. Se este raciocínio faz tender ao infinito, em We feel Fine. An Exploration of Human Emotion, in Six Movements de Jonathan Harris e Sep Kamvar ( $\underline{w w w}$.wefeelfine.org), uma geografia (e não uma história) é criada e tendenciosa a tal infinitude. Em tempo real, um cruzamento de dados sem limites.

O que foi mapeado nos três anos em que o projeto se deu foi a iminência dos sentimentos pessoais de cada personagem inscrito na rede mundial de blogs e outros sítios das redes sociais, cruzando-os das mais diferentes maneiras. O que restou após esses três anos foi um sítio - amontoado de sentimentos, visualmente complexos: traços. Um território, um traço geográfico de uma história. Uma paisagem complexa representada não como espaço, mas uma teia de relações no tempo por uma imagem (Figuras 07 a 10). 


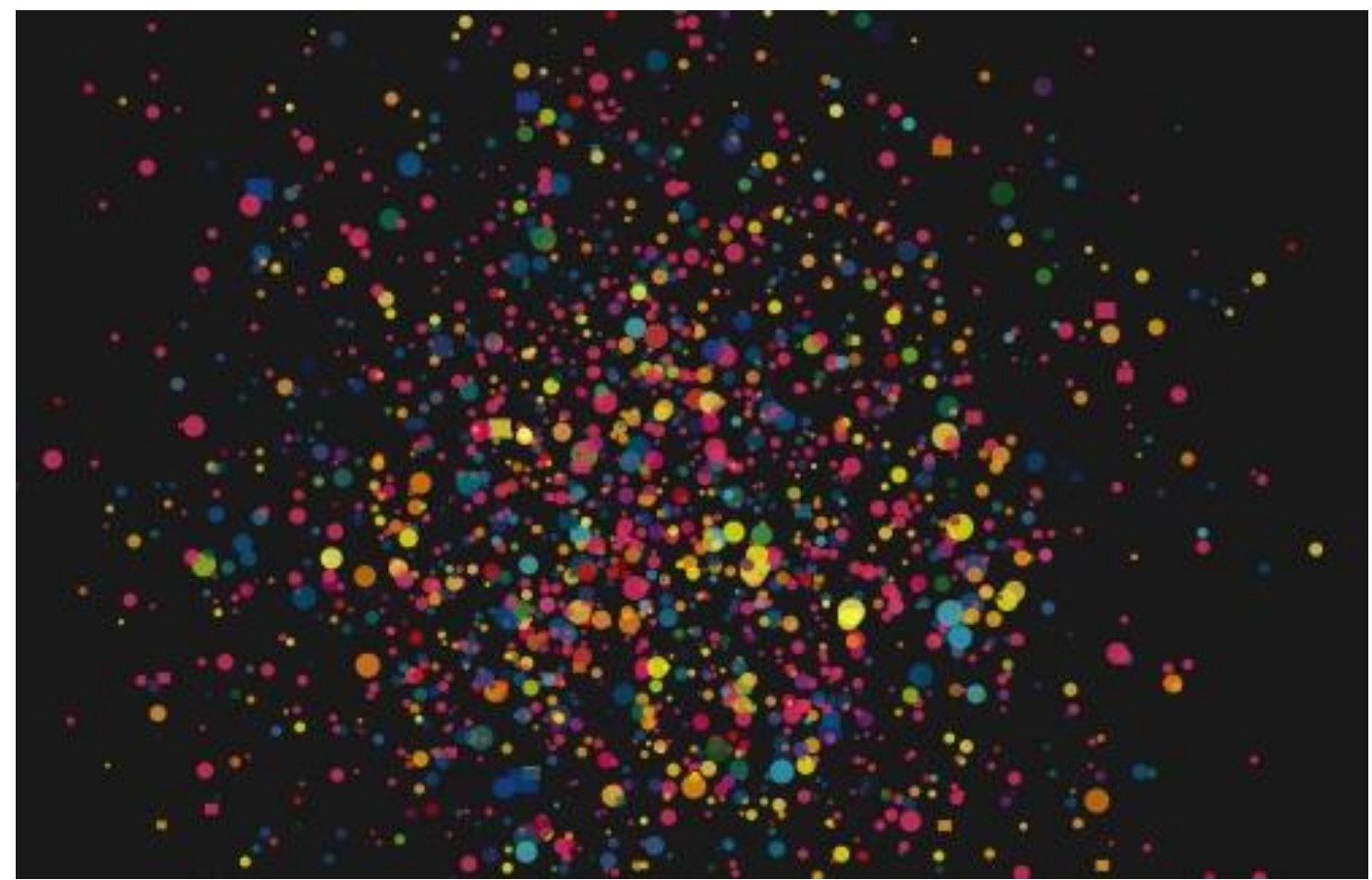

Figura 07: Imagens do site.

Fonte: http://www.smashingmagazine.com/2007/08/02/data-visualization-modern-approaches/, acessado em: 17/01/2011.

Ao teclar na palavra "beautiful" ou num círculo de cor amarela, é aberta uma página com dados a respeito de quantas pessoas escrevem a palavra "beautiful" em seus blogs pessoais, ou qual a porcentagem de pessoas "beautiful" no planeta tendo como contexto blogs, ou de acordo com o tamanho do círculo, porcentagens sobre diversos assuntos relacionados a palavra ou, ainda, o que se diz usando a palavra "beautiful' nas redes sociais, bem como o sentido dado - ironias, paródias, elogios, substantivações etc.

Pode-se argumentar que não há como ter uma medida precisa ou que todas as porcentagens, gráficos e visualizações são apenas projeções potenciais do que pode existir. Além disso, as redes sociais não dizem exatamente o que se passa, ou quais sentimentos as pessoas têm sobre os mais diversos temas apresentados no sítio. Quem escreve nestas redes, finge. Mas aí justamente reside a sua potencialidade: é um modo de lidar com o infinito e mesmo com a multiplicidade de leituras que podem surgir das mais diferentes identificações: uma exposição do modus operandi da linguagem - visual, fotográfica, videográfica ou outra - usada para lidar, muitas vezes, com o que Ihes é desconhecido. Tornado geográfica, no 
espaço da tela, num tempo não-histórico, pois não há datas ou períodos cronológicos, não há passado ou futuro, tem-se apenas o devir constante das formas e significados ocupando espaços geográficos da tela do computador. Uma imagem relacional de como se constróem relações que potencialmente poderiam aferir dados relativos a espaço. Tal obra se torna instrumento para pensar a paisagem: não uma imagem estática, mas dinâmica produzida por vários agentes e interesses, quando não desejos. Na sua consideração mapa ou como uma cartografia de momentos, têm-se iminências, interrompidas e não inacabadas. Por que iminência?
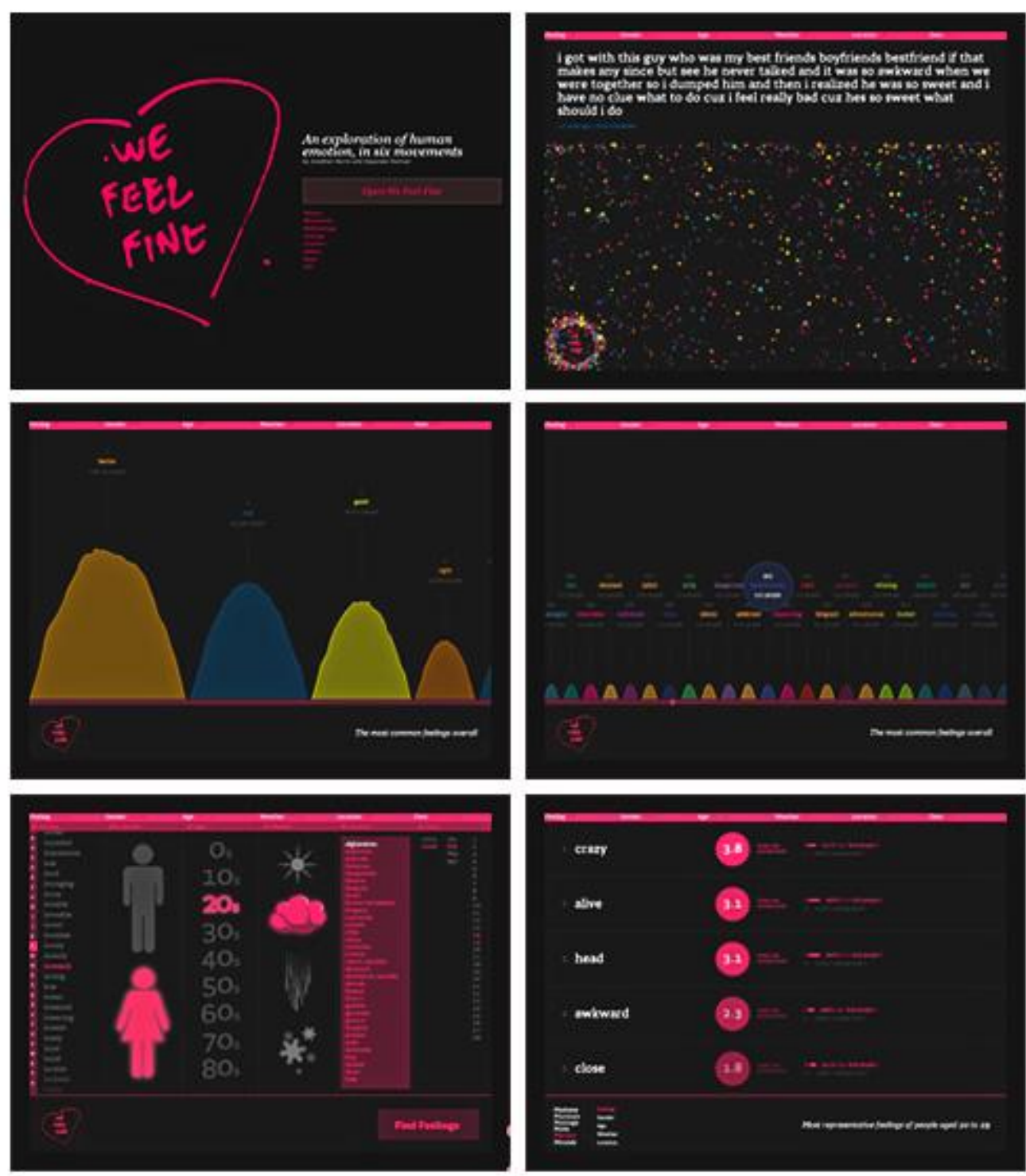

Figura 08: Imagens do site.

Fonte: http://www.tikirobot.net/wp/2006/06/21/we-feel-fine/, acessado em 17/01/2011. 


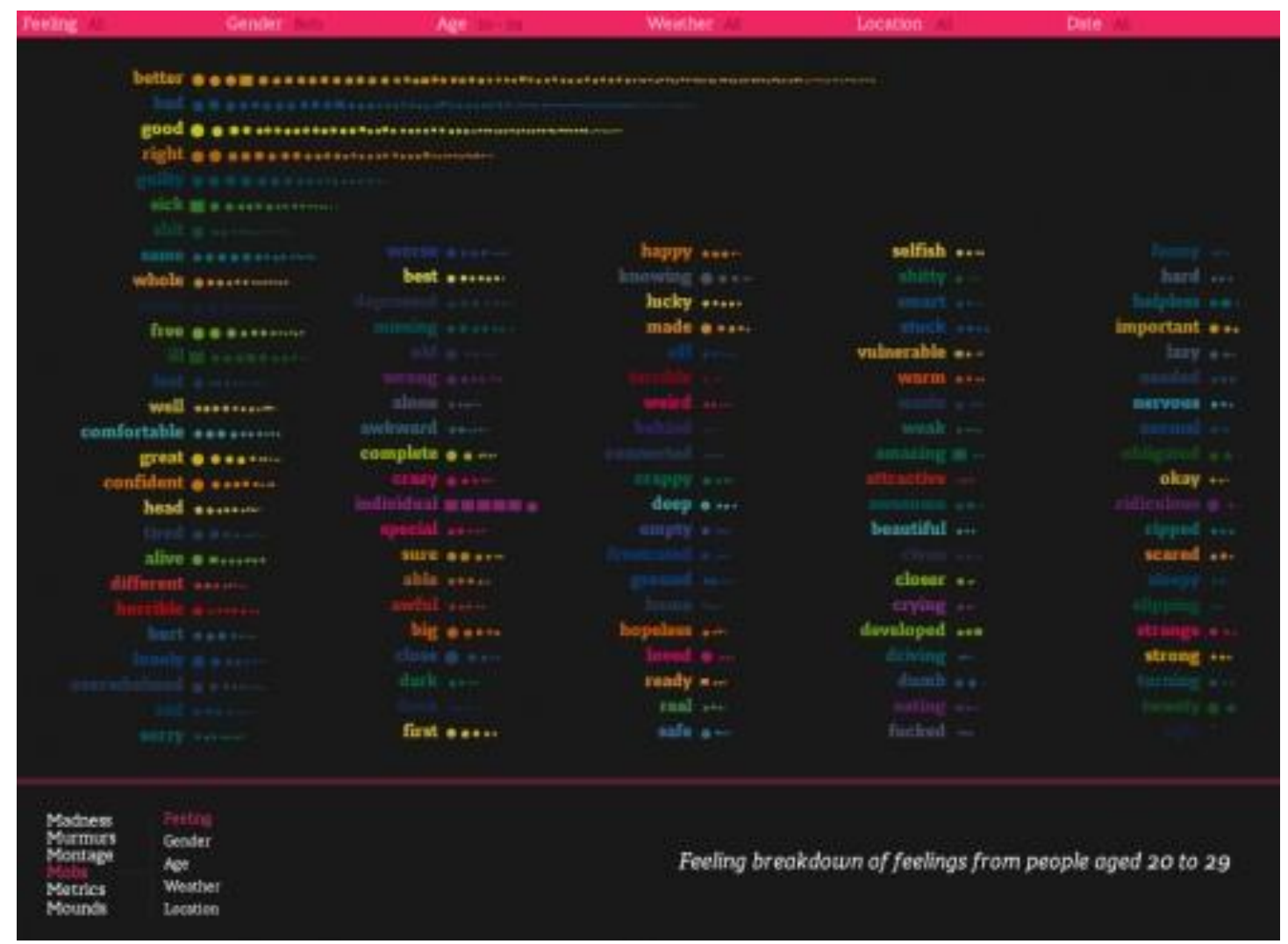

Figura 09: Imagens do site.

Fonte: http://consumerbeat.wordpress.com/category/universo-online/page/3/, acessado em $17 / 01 / 2011$.

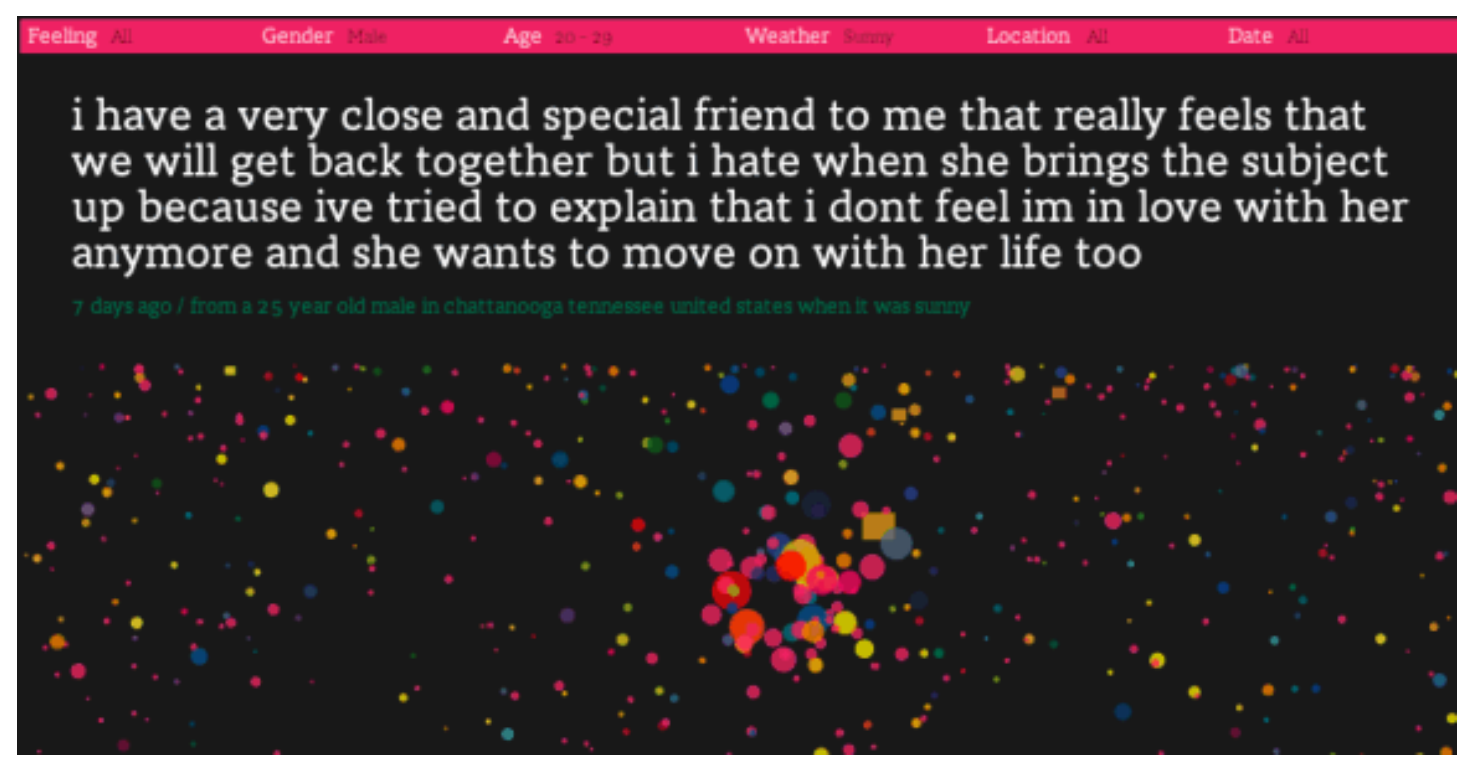

Figura 10: Imagens do site.

Fonte: http://googlesystem.blogspot.com/2007/04/visualizing-human-feelings.html, acessado em $17 / 01 / 2011$. 
No movimento de postagens de blogs e outras redes sociais cobertas por este sítio não há vidas prontas, mas uma paisagem da vida em processo. Em We Feel Fine tem-se não nomes prontos, mas sempre entre o que é e o que pode vir a tornar-se. A iminência do movimento guardado no movimento da própria palavra. A potência do conceito "iminência" está em seu paradoxo: é morte, mas não realizada: este é o movimento intenso a ser cartografado.

Este paradoxo ou espasmo é pedagógico na medida em que atesta a capacidade deste sítio como meio, possibilitar relações e resultados os mais diversos. Numa livre associação dada por nuvens de informação, constróem-se jogos em que paisagens sempre temporárias e não tomadas como "verdade" são formadas.

\section{CONSIDERAÇÕES FINAIS: DO SOCIAL AO HUMANO... E VICE-VERSA}

Estranhamente, ao pensar cartografias como índices de medida coletivamente compreendidos do mundo, associa-se tal compreensão a uma leitura/tradução sem possíveis erros. Ler um mapa significa localizar-se com precisão; ler um atlas, dominar totalmente um lugar. Precisão e total como nomeações de Poder. Compreensões sociais cujo elemento social é definido como coletividade homogênea.

Porém, ler é processo aberto onde o tecido social explode em fragmentos dados por sujeitos, cada um com sua leitura. Uma multidão de sujeitos que implode qualquer tentativa de nomeação ou cartografia total e precisa. Tais mapas e atlas são justamente abertos não porque são de fácil assimilação e emPoderamento, mas porque discutem o próprio território como espaço especialmente narrativo. Porque transformam a idéia de social em pequenas unidades humanas irredutíveis produzidas a cada jogada, a cada paisagem produzida, a cada nova imagem de coletividade prestes a esfacelar, a cada mundo real.

\section{REFERÊNCIAS}

ABALOS, Iñaki. $O$ que é a paisagem. Disponível em: http://www.vitruvius.com.br/revistas/read/arquitextos/05.049/572/pt. Acesso em 03 de junho de 2013. 
AUGÉ, Marc. Não lugares. Uma antropologia da supermodernidade. Campinas/SP: Papirus, 2007. Por uma antropologia da mobilidade. São Paulo: UNESP, 2010.

BENJAMIN, Walter. Passagens. Belo Horizonte, São Paulo: EdUFMG, Imprensa Oficial, 2006.

CAUQUELLIN, Anne. A invenção da paisagem. São Paulo: Martins Fontes, 2008.

CHRISTOV-BAKARGIEV, Carolyn. DOCUMENTA 13. Catalog III/3, The Guidebook. Ostfildern/Alemanha:Hatje Cantz, 2012.

DELEUZE, Gilles. A lógica do sensação. São Paulo: Jorge Zahar, 2007.

FREIRE, Cristina. Contexturas: Sobre artistas e/ou antropólogos IN: LAGNADO, Lisette, PEDROSA, Adriano (Orgs.). $27^{\text {a }}$ Bienal de São Paulo: Como viver junto. São Paulo: Fundação Bienal, 2006.

MACHADO, Roberto. Deleuze, Arte e Filosofia. Rio de Janeiro: Zahar, 2009. 